\title{
MEASUREMENT OF SYNTHESIS RATE OF LONG-CHAIN ACYL-COENZYME A ESTER IN BOVINE LIVER BY HIGH-PERFORMANCE LIOUID CHROMATOGRAPHY
}

\author{
T. Mitsuhashi, M. Mitsumoto, Y. Yamashita ${ }^{2}$ \\ and S. Ozawa \\ Chugoku National Agricultural Experiment Station, Livestock \\ Division, Kawai-Cho Oda-Shi Shimane-Ken 694, Japan
}

\begin{abstract}
Summary
A high performance liquid chromatographic procedure is described for the direct determination of the picomole amount of palmitoyl-Coenzyme A and stearoyl-Coenzyme A, using a stainless steel column packed with C-18 derivatized porous silica $(5 \mu \mathrm{m})$, an isocratic elution with a mixture of $33 \mathrm{mM} \mathrm{KH}{ }_{2} \mathrm{PO}_{4}$ /acetonitrile as a mobile phase and a UV detector. The long-chain acyl-Coenzyme A esters were determined in incubated microsomal fractions of a bovine liver to demonstrate the utility of this method for monitoring acyl-CoA synthesis in biological samples. The reaction rate of palmitate was higher than that of stearate. After a 60 minute incubation period, the generated amount of palmitoyl-Coenzyme A and stearoyl-Coenzyme A were approximately 70 and $20 \mathrm{n} \mathrm{mol} / \mathrm{mg}$ microsomal protein, respectively. The advantage of this method are in that no decomposition of the CoA esters is involved, while the constituent molecular species is detected.
\end{abstract}

(Key Words: HPLC, Acyl CoA, Bovine Liver)

\section{Introduction}

The recent introduction of $\mathrm{C}-18$ derivatized porous silica microparticles for reverse-phase high performance liquid chromatography (HPLC) has facilitated the assay of CoenzymeA(CoASH) in biological extracts (Ingebretsen and Farstad, 1980). The method was adequate for the measurement of free CoASH after controlled alkaline hydrolysis of the perchloride insoluble materials from biological samples, thus giving an indication of the amount of acyl-CoA derivatives in the sample (Ingebretsen et al, 1979). However, with this method, it was impossible to determine the individual molecular species of acyl portions of the derivatives and to separate $\mathrm{COASH}$ from acyl$\mathrm{CoA}$ derivatives without degradation of free CoASH (Ingebretsen et al, 1979). In view of these problems during determination of acyl-CoA

\footnotetext{
${ }^{1}$ Address reprint requests to Mr. T. Mitsuhashi, Chugoku National Agricultural Experiment Station, Livestock Division, Kawai-Cho Oda-Shi Shimane-Ken 694, Japan.

${ }^{2}$ Present address: Hokuriku National Agricultural Experiment Station, Jouetsu-Shi Niigata-Ken 643-01, Japan

Received May 6, 1988

Accepted September 7, 1988
}

esters in biological samples, it is important to develop a simple method which provides sensitive direct measurement, detecting the constituent molecular species. In this communication, the details of our procedure used for the determination and identification of palmitoyl Coenzyme $\mathrm{A}$ (P-CoA) and stearoyl Coenzyme A (S-CoA) by HPLC is described. When combined with enzymatic synthesis, this method provides a quantitative assessment of the conversion of long chain fatty acid to the corresponding acyl-CoA ester.

\section{Materials and Methods}

\section{Chemicals}

CoASH was obtained from Kohjin Co. Ltd. (Tokyo, Japan). P-CoA and S-CoA were purchased from Pharmacia P-L Biochemicals (Uppsala, Sweden). ATP and L-cysteine were supplied by Nakarai Chemicals Ltd. (Kyoto, Japan). All other reagents were commercially available and of highest purity.

\section{Chromatographic conditions}

A constant volume high-performance liquid chromatographic pump equipped with UV detector (Model LC-4A, Shimadzu, Kyoto, Japan) was 
.

. 

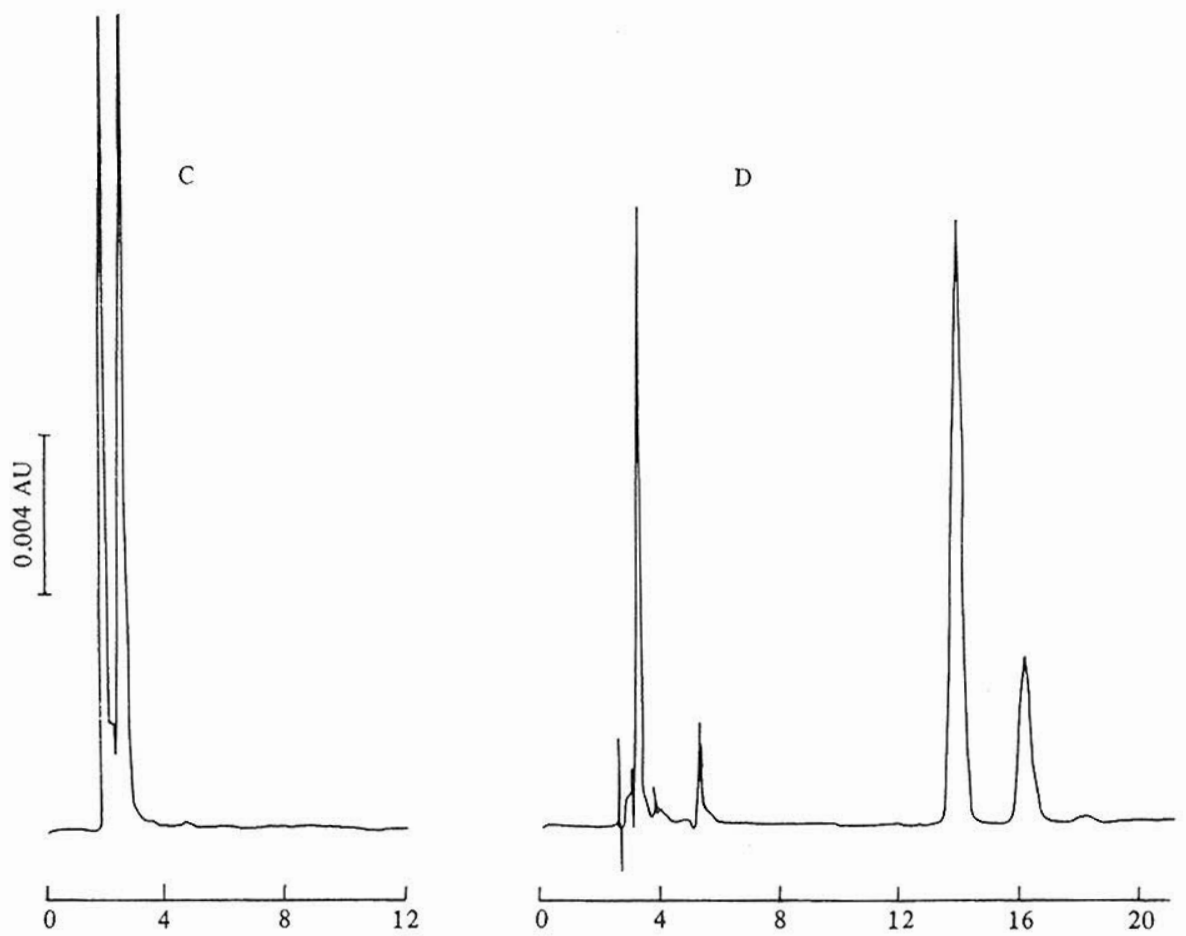

Retention Time (min)

Figure 1. Figure 1A. The HPLC chromatogram of $230 \mathrm{p} \mathrm{mol}$ of palmitoyl CoenzymeA (P-CoA) before alkaline hydrolysis with a retention time of $(\mathrm{tR}=) 4.9 \mathrm{~min}$. P-CoA $(0.23 \mu \mathrm{mol})$ was dissolved in $10 \mathrm{ml}$ of $10 \mathrm{mM}$ aqueous solution of 2-mercaptoethanol and $5 \mathrm{ml}$ aliquot of the solution was diluted to $10 \mathrm{ml}$ with distilled water before the injection of $20 \mu \mathrm{l}$ into a $15 \mathrm{~cm} \times 0.6 \mathrm{~cm}$ column of 5 micro meter ultrasphere ODS. Individual components were eluted isocratically at $32^{\circ} \mathrm{C}$ with a flow rate $1 \mathrm{ml} / \mathrm{min}$, using a solvent mixture comprised of $33 \mathrm{mM} \mathrm{KH}_{2} \mathrm{PO}_{4}$ /acetonitrile $(30: 70, \mathrm{v} / \mathrm{v})$. UV absorbance was monitored at $260 \mathrm{~nm}$ with 0.02 absorbance until full scale. Figure 1B. The eluate of the solution of figure $1 \mathrm{~A}$ by the solvent stock comprised of $220 \mathrm{mM} \mathrm{KH}_{2} \mathrm{PO}_{4}$ / methanol/thiodiglycol (100:12:0.05, v/v/v) at room temperature. HPLC column and flow rate were the same as Fig. 1 A. UV absorbance was monitored at $254 \mathrm{~nm}$. Figure 1C. Disappearance of P-CoA after alkaline hydrolysis. The counterpart $5 \mathrm{ml}$ solution of figure $1 \mathrm{~A}$ was hydrolyzed at $\mathrm{pH} 12.7$ with $1 \mathrm{~N} \mathrm{KOH}$, for $60 \mathrm{~min}$ at $40^{\circ} \mathrm{C}$. After cooling on ice water, the $\mathrm{pH}$ of the suspension was readjusted to 5 with $6 \%(\mathrm{v} / \mathrm{v})$ perchloric acid containing $0.5 \mathrm{M}$ triethanol-amine $-\mathrm{HCl}$ and diluted to $10 \mathrm{ml}$ as decribed for figure 1A. $20 \mu \mathrm{l}$ aliquot was injected and separated as described for figure $1 \mathrm{~A}$. Figure D. Appearance of CoA ( $t R=16.2 \mathrm{~min}$ ) after alkaline hydrolysis of P-CoA. $20 \mu \mathrm{l}$ aliquot of the solution of figure $1 \mathrm{C}$ was injected and separated as described for figure $1 \mathrm{~B}$. 


\section{MITSUHASHI ET AL.}

Enzymatic synthesis of CoA derivatives of long chain fatty acids

A bovine liver, obtained from a 14 month old Japanese Black steer which had been fasted for 2 days, was used. Fractional collection of enzymes from the liver and the enzymatic synthesis of CoA derivatives of palmitic acid and stearic acid were performed by the method of Kornberg and Pricer (1953).

\section{Protein determination}

Protein content of the microsome fraction of bovine liver was determined by the Folin-Ciocalteu phenol reagent (Lowry et al., 1951) using bovine serum albumin as standard.

\section{Results and Discussion}

\section{Optimization of HPLC conditions}

Using a micro particulate reversed-phase column, the acetonitrile mobile phase and commerical preparation of palmitoyl-CoA ( $\mathrm{P}-\mathrm{CoA})$, a possible peak of $\mathrm{P}-\mathrm{CoA}$ with the retention time of $(t R=) 4.9$ min was collected (figure 1A). Since the injected sample contained a reducing agent and different compounds that absorbed at $260 \mathrm{~nm}$, peaks were always observed shortly after sample injection. When the sample was eluted by methanol mobile phase adequate for $\mathrm{CoASH}$ analysis, CoASH ( $t R=16.2 \mathrm{~min}$ ) was slightly detected (figure $1 \mathrm{~B}$ ). The reducing agent 2-mercaptoethanol was eluted as two peaks, with the retention time of $5.3 \mathrm{~min}$ and $14.0 \mathrm{~min}$, respectively (figure 1B). A possible peak of P-CoA was not obtained on the chromatogram during the 3 hours when the sample was eluted by the methanol mobile phase. Corkey et al. (1981), using $\mathrm{C}_{18}$ column for assay of short-chain acyl CoA, reported that the more lipopylic compounds were more strongly absorbed in the column and required a higher methanol concentration for removal. However, in our trial with the highest methanol concentration $(99 \%)$, a possible peak of the longchain acyl-CoA was not collected within a convenient retention time, although a broadened indistinct peak was obtained after the given time. In practice, acetonitrile is more effective than methanol for the elution of long-chain acyl-CoA from $\mathrm{C}_{18}$ column. The retention time of longchain acyl-CoA was not altered by phosphate but by acetonitrile content in the mobile phase solvent, and was shortened by increasing acetonitrile content in the solvent. It should be noted that a higher acetonitrile with an inappropriate high concentration of phosphate causes recrystallization of phospholic acid in the mobile phase during analysis, which leads to damage on HPLC column, rendering it useless. On the other hand, the phosphate buffer is indispensable in keeping mobile phase $\mathrm{pH}$ at approximately 5 in order to avoid

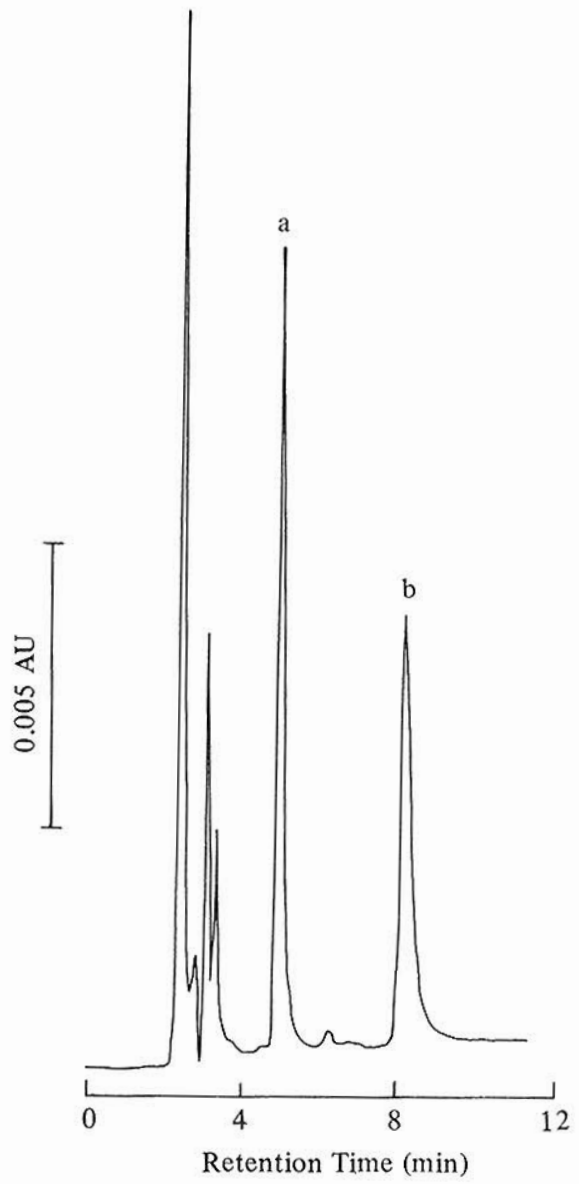

Figure 2. Separation of P-CoA and stearoyl Coenzyme A (S-CoA). P-CoA (approx. $0.75 \mu \mathrm{mol}$ ) and S-CoA (approx. 0.75 $\mu \mathrm{mol})$ were dissolved in a $10 \mathrm{ml}$ of 10 $\mathrm{mM}$ aqueous solution of 2-mercaptoethanol. The $3 \mu \mathrm{l}$ of the solution was injected and separated using the chromatographic condition given for figure $1 A$. The letters $a$ and $b$ refer to the $P$. CoA and S-CoA, respectively. 
destruction of acyl-CoA ester during analysis. The phosphate and acetonitrile content had to be balanced in the mobile phase for determining the most convenient conditions for sample analysis. $\mathrm{S}$-CoA was eluted as a distinct peak ( $\mathrm{tR}=8.3 \mathrm{~min})$, completely separated from the proposed peak of $\mathrm{P}-\mathrm{CoA}(\mathrm{tR}=4.9 \mathrm{~min})$ with the appropriate flow rate and phosphate buffer: acetonitrile ratio (figure 2).

\section{Identification of acyl-CoA esters}

Peak identification was accomplished not only by alkaline hydrolysis but by enzymatic synthesis of acyl CoA esters. After alkaline hydrolysis manipulation in the solution of $\mathrm{P}-\mathrm{CoA}$, a possible peak of $\mathrm{P}-\mathrm{CoA}$ in figure 1A disappeared (figure 1C), whereas the peak corresponding to $\mathrm{CoASH}(\mathrm{tR}=$ $16.2 \mathrm{~min}$ ) appeared (figure 1D). This suggests that the proposed peak of $\mathrm{P}-\mathrm{CoA}$ in figure $1 \mathrm{~A}$ originates from $\mathrm{CoA}$ derivative. Similar series of experiments were performed using samples containing S-CoA. After the alkaline hydrolysis of the
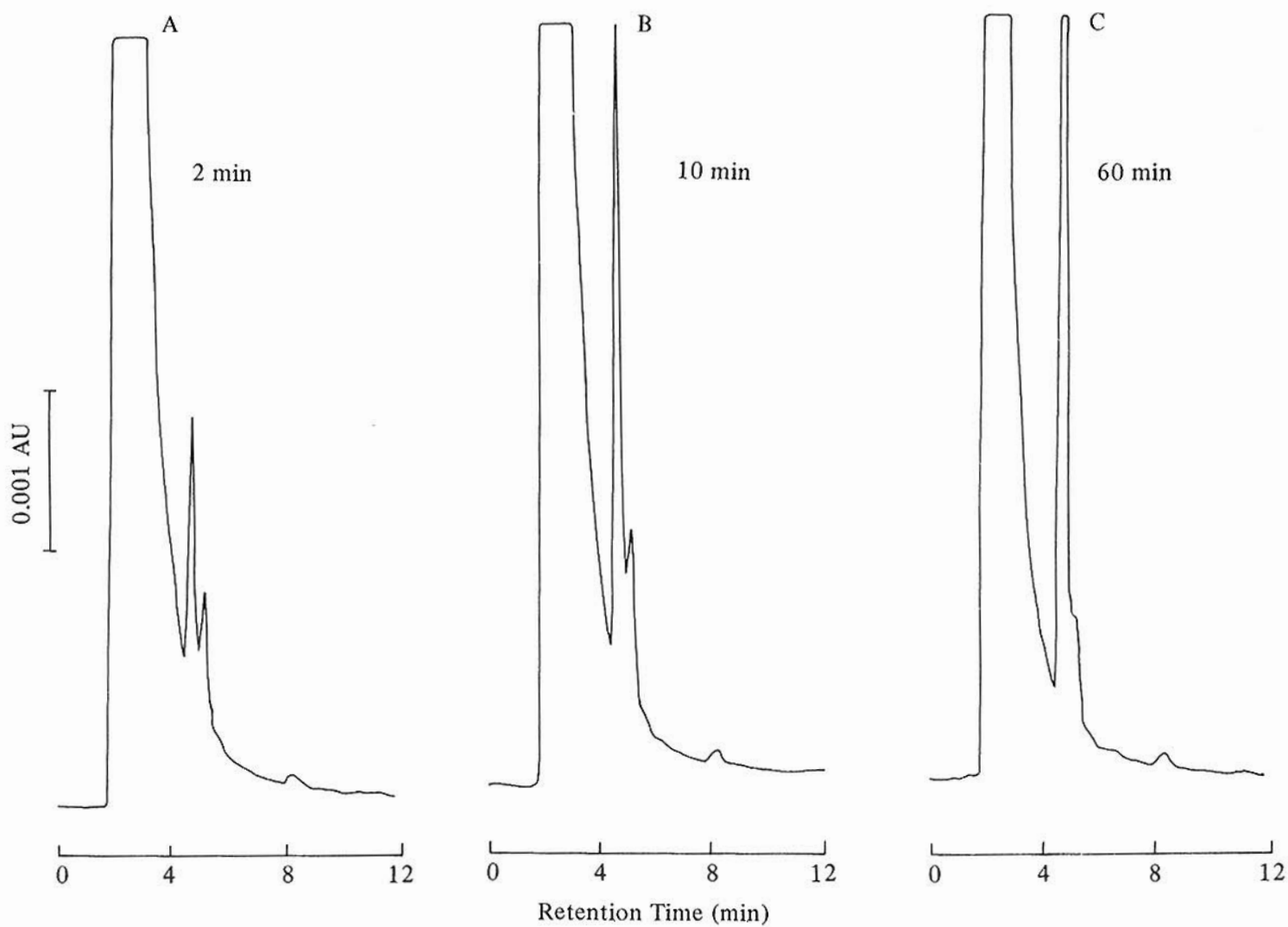

Figure 3. Chromatogram of enzymatically synthesized P-CoA (tR=4.9 $\mathrm{min}$ ) in microsomal fraction from bovine liver. The incubation mixture contained $0.8 \mathrm{ml}$ of palmitate $(0.02 \mathrm{M}$ palmitic acid), $2.0 \mathrm{ml}$ of ATP $(0.02 \mathrm{M}), 1.6 \mathrm{ml}$ of CoA $(0.0034 \mathrm{M}, 94$ percent pure), $0.6 \mathrm{ml}$ of cysteine $(0.2 \mathrm{M}), 0.4 \mathrm{ml}$ of $\mathrm{NaF}(0.5 \mathrm{M}), 0.2 \mathrm{ml}$ of $\mathrm{MgCl}_{2}(0.3 \mathrm{M}), 0.8 \mathrm{ml}$ of phosphate buffer $(0.5 \mathrm{M}, \mathrm{pH} 7.4), 0.6 \mathrm{ml}$ of lyophilized residue fraction (10.3 mg protein per $\mathrm{ml}$ ) and $1 \mathrm{ml}$ of water. Incubation was at $40^{\circ} \mathrm{C}$ for $60 \mathrm{~min}$. Aliquots of $0.5 \mathrm{ml}$ were taken at $2 \mathrm{~min}, 10 \mathrm{~min}, 60 \mathrm{~min}$ and heated in $60^{\circ} \mathrm{C}$ bath for $3 \mathrm{~min}$ to inactivate the enzymes, then chilled to $0^{\circ} \mathrm{C}$ and diluted to $2 \mathrm{ml}$ with the solvent mixture used for figure $1 \mathrm{~A}$. After centrifugation at $1600 \mathrm{~g}$ for $15 \mathrm{~min}, 20 \mu \mathrm{l}$ aliquots of the supernatant were injected and separated using the chromatographic condition used for figure $1 \mathrm{~A}$. 
sample, the proposed peak of S-CoA disappeared while CoASH peak appeared.

Definite proof of the composition of the proposed peak of P-CoA and S-CoA in the chromatogram was obtained in experiment with the enzymatic synthesis of $\mathrm{CoA}$ derivatives of palmitate and stearate. After the addition of palmitate into microsomal fraction and incubation at $40^{\circ} \mathrm{C}$, a peak having identical retention time of the proposed peak of P-CoA appeared and continuously increased (figure $3 \mathrm{~A}, \mathrm{~B}, \mathrm{C}$ ). Similarly, addition of stearate instead of palmitate resulted in enlargement of the peak having identical retention time of the proposed peak of S-CoA (figure $4 \mathrm{~A}, \mathrm{~B}, \mathrm{C}$ ). These phenomena suggest that the proposed two peaks definitely originate from P-CoA and S-CoA, respectively.
Quantitation and measurement of long-chain acylCoA synthesis

The most widely used procedure for the determination of long-chain acyl-CoA in biological samples was the measurement of liberated $\mathrm{CoASH}$ after alkaline hydrolysis of perchloride insoluble material from the sample (Ingebretsen et al., 1979). However, in our experiment, complete hydrolysis of acyl-CoA induced innegligible destruction of liberated CoASH, even when the alkaline hydrolysis was performed by adding a recommended reducing agent into the sample. Since precise measurement of acyl-CoA by alkaline hydrolysis procedure had to be performed by calculating the total amount of liberated and intact $\mathrm{CoASH}$, and the unknown degradation product of $\mathrm{CoASH}$, we thought that the alkaline
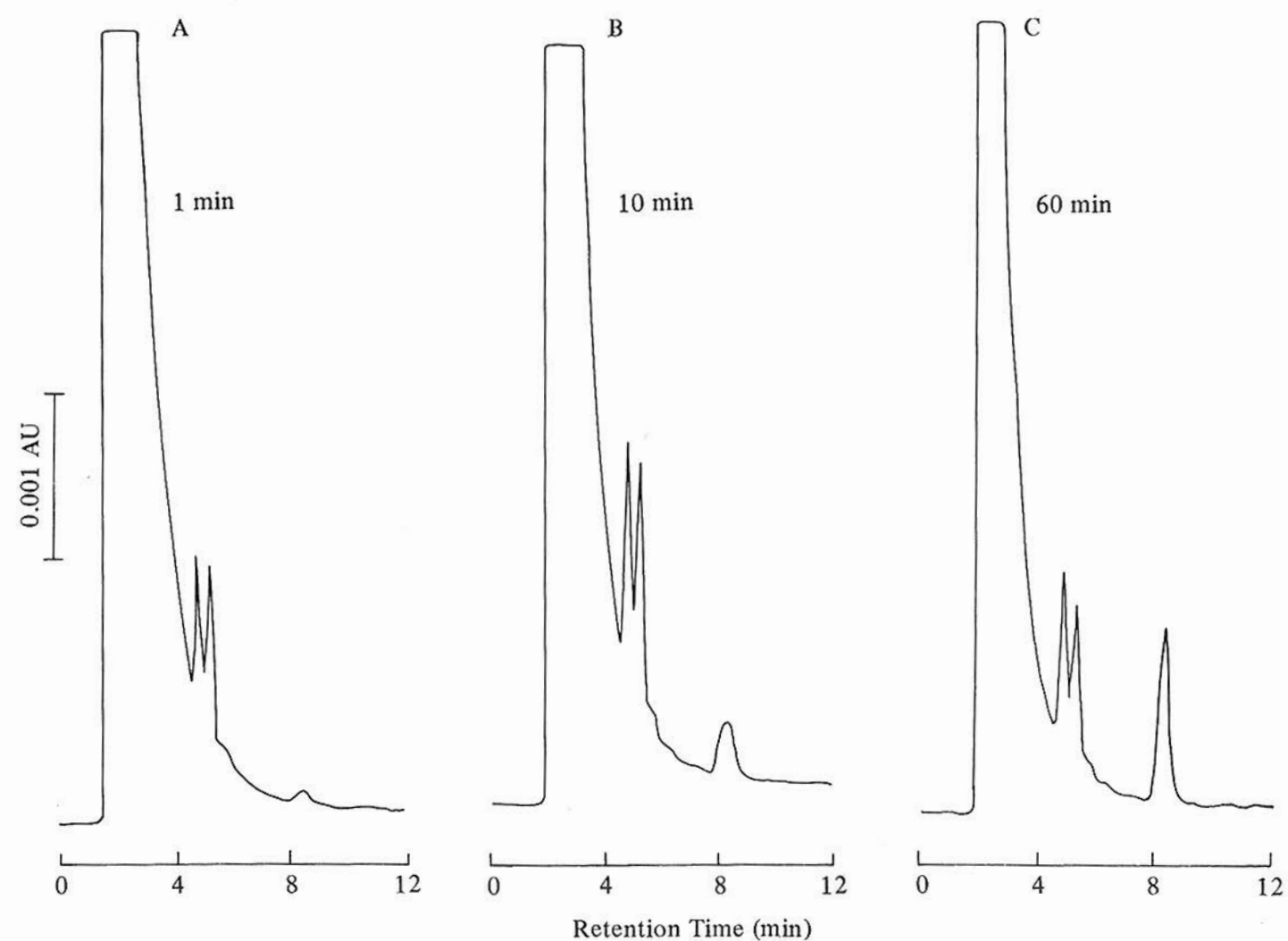

Figure 4. Chromatogram of enzymatically synthesized $\mathrm{S}-\mathrm{Co} A(t R=8.3 \mathrm{~min}$ ) in microsomal fraction from bovine liver. The $0.8 \mathrm{ml}$ of stearate $(0.02 \mathrm{M}$ stearic acid) was added instead of palmitate to the incubation medium used for figure 3 . The injected aliquots were prepared as described for figure 3 and separated using the chromatographic condition used for figure $1 \mathrm{~A}$. 


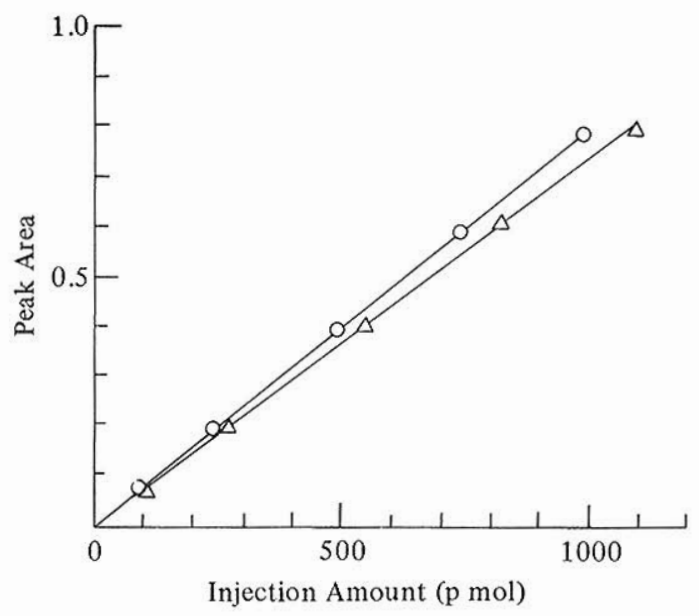

Figure 5. Standard curve for HPLC absorbance assay of P-CoA and S-CoA. P-CoA and S-CoA were dissolved in $0.1 \mathrm{~N}$ potassium phosphate buffer ( $\mathrm{pH} 5.5$ ), respectively and injected into HPLC as described for figure $1 \mathrm{~A}$. The concentration of the acyl-CoA derivative in the solutions were measured spectrophotometrically before the injection. Peak areas are given by the integral of absorbancy at $260 \mathrm{~nm}$. The graphic symbols of circle and triangle refer to P.CoA and S-CoA, respectively.

hydrolysis procedure was not convenient for the microanalysis of long-chain acyl-CoA. The advantage of our substitute method is that no decomposition of the CoA esters is involved in the process.

Excellent linearity was obtained between the injected amount of the individual authentic acylCoA ester and the integrated peak area up to at least $1000 \mathrm{p} \mathrm{mol}$ (figure 5). It was necessary to dissolve the COA esters in a $0.1 \mathrm{~N}$ potassium phosphate buffer ( $\mathrm{pH} 5.5)$ in order to obtain the standard curve which can extrapolate to the origin. Apparent losses of peak area corresponding to those esters were observed when dissolved in distilled water. As seen in figure 2 with the amount of individual standard of $230 \mathrm{p} \mathrm{mol}$, peak height of $50 \%$ full scale corresponded to $150 \mathrm{p} \mathrm{mol}$ to $300 \mathrm{p}$ mol of P-CoA or S-CoA. The acyl-CoA peak of 5\% full scale can be measured, so that the lower limit of detection would be approximately $30 \mathrm{p} \mathrm{mol}$.

Quantitation of individual acyl-CoA esters in a

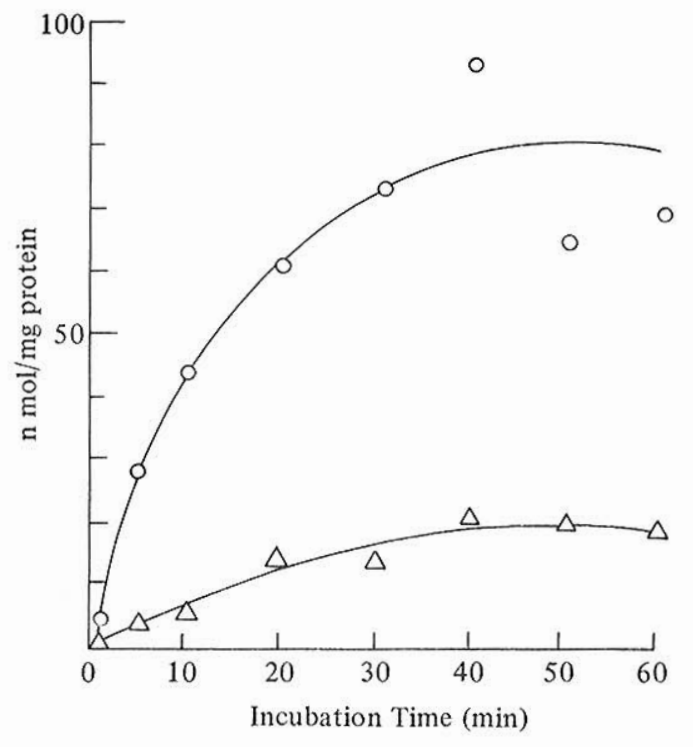

Figure 6. Time course of long chain acyl-CoA synthesis of a bovine liver microsomal fraction. Aliquots of reaction mixture were prepared as described for figure 3 or figure 4 and separated using the chromatographic conditions used for figure 1A. The graphic symbols of circle and triangle refer to P.CoA and S-CoA, respectively.

biological sample was achieved by comparing the peak area of a known amounts of individual acyl-CoA standards with the area of peaks having retention times corresponding to those of the standards. The kinetic feature of the acyl-CoA synthesis in microsomal fraction from bovine liver was obtained by the injection of aliquots picked up at certain intervals from the incubated sample (figure 6). The reaction rate of palmitate was heigher than that of stearate. After $60 \mathrm{~min}$. incubation, the generated amount of P-CoA and SCoA were approximately 70 and $20 \mathrm{n} \mathrm{mol} / \mathrm{mg}$ microsomal protein, respectively. The specificity of acyl-CoA synthesis towards these two fatty acids is in agreement with those of Massaro and Lennartz (1965) with bacteria, Brindley and Hubscher (1966) with cat and guinea pig, Fande and Mead (1968) with rat and Tanaka et al. (1979) with purified long-chain acyl-CoA synthetase from rat liver. The synthesized amount of P-CoA, although varying slightly, is in general agreement 


\section{MITSUHASHI ET AL.}

with the experiment of Kornberg and Pricer (1953) which measured radioactive palmitate incorporation into $\mathrm{P}-\mathrm{CoA}$ in guinea pigs.

To our knowledge, this is the first report where kinetic feature of long-chain acyl-CoA synthesis has been monitored by HPLC method. This method should provide useful information for detailed understanding of several metabolic pathways which employ long-chain acyl-CoA esters.

\section{Acknowledgments}

The authors wish to thank Dr. T. Matsui, Dr. K. Suzuki and Dr. T. Harumoto of Shimane University for their invaluable advice and assistance in the preparation of this paper.

\section{Literature Cited}

Brindley, D.N. and G. Hubscher. 1966. The effect of chain length on the activation and subsequent incorporation of fatty acid into glycerides by the small intestinal mucosa. Biochim. Biophys. Acta. 125:92. Corkey, B.E., M. Brandt, R.J. Williams and J.R. William- son. 1981. Assay of short-chain acyl coenzyme A intermediates in tissue extracts by high-performance liquid chromatography. Anal. Biochem. 118:30.

Ingebretsen, O.C. and M. Farstad. 1980. Direct measurement of free coenzyme A in biological extracts by reversed-phase high-performance liquid chromatography. J. Chromatogr. 202:439.

Ingebretsen, O.C., P.T. Norman and T. Flatmark. 1979. Determination of $\mathrm{CoASH}$ by high-performance liquid chromatography and its application in the assay of long-chain acyl-CoA derivatives. Anal. Biochem. 96:181.

Kornberg, A. and W.E. Pricer, Jr. 1953. Enzymatic synthesis of the coenzyme A derivatives of long chain fatty acids. J. Biol. Chem. 204:329.

Lowry, O.H., N.J. Rosebrough, A.L. Farr and R.J. Randall. 1951. Protein measurement with the folin phenol reagent. J. Biol. Chem. 193:265.

Massaro, E.J. and W.J. Lennartz. 1965. The partial purification and characterization of a bacterial fatty acyl coenzyme A synthetase. Biochemistry. 4:85.

Pande, S.V. and J.F. Mead. 1968. Long chain fatty acid activation in subcellular preparations from rat liver. J. Biol. Chem. 243:352.

Tanaka, T., K. Hosaka, M. Hoshimaru and S. Numa. 1979. Purification and properties of long-chain acyl-coenzyme-A synthetase from rat liver. Eur. J. Biochem. 98:165. 